\title{
Socio-Demographic Profile and Psychiatric Morbidity of Flood Victims in a Mental Health Camp
}

\author{
Bilal Ahmad Bhat ${ }^{* 1}$, Shabir Ahmad Dar ${ }^{1}$, Mohammad Ashraf Khan ${ }^{2}$ and Altaf Ahmad Malla \\ ${ }^{1}$ Department of Psychiatry, government Medical College, Shrinagar, India \\ ${ }^{2}$ Department of Orthopedics, Government Medical college, Shrinagar, India
}

\section{Abstract}

Background and objectives: Floods have potentially a negative impact, not only on the physical health but also on the mental health of the affected population. Our aim was to find the pattern of psychiatric morbidity in the flood victims who visited a mental health camp.

Methods: This was a cross sectional study, approved by Ethical Committee of government medical college, Srinagar. Written informed consent from the subjects was taken. Semi-structured questionnaire was used to record the socio-demographic status. MINI-International Neuropsychiatric Interview (MINI-Plus) was used to assess the psychiatric diagnosis.

Results: A total of 115 subjects visited the camp. Most of them belonged to $40-49$ years age group (41.74\%), females $(66.96 \%)$ out-numbered males. Most of patients belonged to nuclear families $(55.65 \%) .66(57.39 \%)$ of our subjects had major depressive disorder, $14(12.17 \%)$ had generalized anxiety disorder, $7(6.09 \%)$ had panic disorder, $7(6.09 \%)$ had post-traumatic stress disorder and $5(4.35 \%)$ had adjustment disorder. $16(13.91 \%)$ of our subjects where not found to have any psychiatric disorder.

Conclusion: Large number of people is potentially in need of psychological attention following exposure to a disaster such as floods. The people, who are at potential risk of developing psychiatric disorders such as those in poor health and those who have been relocated, may benefit from targeted mental health services following a disaster like floods. In our study, major depressive disorder was the most common disorder affecting flood victims with $57.39 \%$ of the patients suffering from it.

Keywords: Flood; Psychiatric morbidity; Post traumatic stress disorder

\section{Introduction}

In the first decade of twenty first century, the most common type of disaster globally has been flooding, responsible for almost half of all victims of natural disasters and for economic losses [1]. An increase in frequency and intensity of flooding events is expected due to rising sea levels and more frequent and extreme precipitation events [1,2]. In addition, with increasing urbanization, more people will be exposed to flooding events [3]. Although there is a conflicting evidence with regard to the impact of floods on suicide and substance abuse, but there is potentially negative impact on mental health, with increasing levels of post-traumatic stress disorder (PTSD), anxiety, and depression and this impact is similar in both developed and developing countries [4]. Prevalence of psychiatric disorders, ranging from $8.6 \%$ to $53 \%$ has been reported in studies on victims of floods in the first two years following floods $[5,6]$. In addition to psychological distress, a portion of the physical illnesses experienced by victims may be accounted for these floods [7]. It has been found that the most profound psychosocial effects are long-term, gradual and co-morbid [8]. A study in a remote Korean village found flood-related injury, death of relative or damage to possession as significant risk factors for depression (51\%) and PTSD (22\%) at 18 months post-floods [6]. A similar study in Thailand, ten weeks following an unexpected, severe flood showed that subjects who were exposed to severe loss were four times more likely to report PTSD symptoms [9]. Insight into long term impact of floods on psychiatric disorders can be provided by longitudinal studies, e.g. Norris et al. observed that despite the initial decline in psychiatric symptoms, in the longer term (two years) the prevalence of trauma and depression stabilized at levels much higher than those in the general population [10]. Similar findings were reported in Thailand when an increase in psychiatric symptoms one year following the flood was observed despite a significant downward trend in psychiatric symptoms in the first year [9]. This may be because floods can result in acute and delayed onset of PTSD, with different symptoms emerging at short and long-term [11]. People witnessing a natural disaster may be exposed to high frequency physical injury, threat to or actual loss of life and/or serious continuing financial difficulty which can result in deterioration of psycho-social health in victims of that disaster [1]. Flood victims in Kashmir, more or less, experienced these threats making them more vulnerable towards getting psychiatric impairments. In September 2014, the Kashmir region suffered disastrous floods across many of its districts caused by torrential rainfall. The Indian administrated Jammu and Kashmir, as well as Pakistan administered Azad Kashmir, Gilgit-Baltistan and Punjab were affected by these floods. In Srinagar, most of the city areas were submerged under water. The river Jhelum spilled over submerging Sonwar Bagh, Shivpora, Batwara, Soitang, Lasjan, Padshai Bagh, Natipora, Pandrathan, LalChowk, Rajbagh, Jawahar Nagar, Gogji Bagh and Wazir Bagh neighborhoods of city. The first and the second story of the houses and hotels in Rajbagh that were packed with tourists were submerged. This led to heavy financial, residential and environmental losses. Living in conditions with lack of proper food, shelter, clean drinking water added extra discomfort. Floods with such an impact

*Corresponding author: Bilal Ahmad Bhat, Department of Psychiatry, Government Medical College, Jammu and Kashmir, India, Tel: 917006351640 , 919596272573; Fax: 9086930515; E-mail: bilalahmadbhat69@gmail.com

Received: January 29, 2017; Accepted: May 01, 2018; Published: May 11, 2018

Citation: Bhat BA (2018) Socio-Demographic Profile and Psychiatric Morbidity of Flood Victims in a Mental Health Camp. J Psychiatry 21: 449. doi:10.4172/2378-5756.1000449

Copyright: (c) 2018 Bhat BA. This is an open-access article distributed under the terms of the Creative Commons Attribution License, which permits unrestricted use, distribution, and reproduction in any medium, provided the original author and source are credited 
can have long lasting effects not only on physical but mental health of people as well $[12,13]$. A variety of psychiatric symptoms and disorders can be expected to be present among them. As a preliminary study, we aimed to study the pattern of psychiatric disorders in patients who had been victimized by floods in a mental health camp so that we can get an idea about the psychiatric disorders among flood victims.

\section{Methods}

This was a cross sectional study conducted among the flood victims of 2014 Kashmir floods attending the mental health camp organized by department of psychiatry, government medical college Srinagar in Jawahar Nagar area of Srinagar city four months after the floods. This study was approved by the ethical committee of government medical college Srinagar. Study population comprised of subjects aged 18 years or more who gave the consent for the study. All those subjects who were suffering from any psychiatric disorder prior to the floods were excluded from the study. A semi-structured interview was used to record the socio-demographic profile of the patients. Structured diagnostic interview in the form of MINI-International Neuropsychiatric Interview (MINI-Plus) was used to assess the psychiatric diagnosis [14]. The data about various parameters categorized according to age group, sex, family type, and diagnosis was entered into Microsoft Excel. Statistical analysis was carried out with Statistical Package for Social Sciences (SPSS) 20.0 version.

\section{Results}

Of 115 patients, 38 (33.04\%) were males and 77 (66.96\%) were female, with an approximate male to female ratio of 1:2. Mean age of the subjects was 44.01 years $(\mathrm{SD}=11.080$, with age range of 18 years to 72 years. Subjects in age group 40-49 years constituted the largest proportion with $48(41.74 \%)$ belonging to this age group followed by $30(26.09 \%)$ in $50-59$ years age group and $18(15.65 \%)$ in $30-39$ years age group. $64(55.65 \%)$ of subjects belonged to nuclear families whereas 51 (44.35\%) of subjects were from joint families. $66(57.39 \%)$ of our subjects were working at home (housewife), 29 (25.22\%) were employed, $9(7.83 \%)$ were students and $11(9.57 \%)$ were laborers (Table 1$)$.

\begin{tabular}{|c|c|c|}
\hline Age in years & Number of patients & Percentage \\
\hline$<20$ & 2 & 1.74 \\
\hline $20-29$ & 12 & 10.43 \\
\hline $30-39$ & 18 & 15.65 \\
\hline $40-49$ & 48 & 41.74 \\
\hline $50-59$ & 30 & 26.09 \\
\hline$\geq 60$ & 5 & 4.35 \\
\hline Total & 115 & 100 \\
\hline Sex of patient & Number of patients & Percentage \\
\hline Male & 38 & 33.04 \\
\hline Female & 77 & 66.96 \\
\hline Total & 115 & 100 \\
\hline Family Type & Number of patients & Percentage \\
\hline Nuclear & 64 & 55.65 \\
\hline Joint & 51 & 44.35 \\
\hline Total & 115 & 100 \\
\hline Occupation & Number of Patients & Percentage \\
\hline House-wife & 66 & 57.39 \\
\hline Employed & 29 & 25.22 \\
\hline Laborer & 11 & 9.56 \\
\hline Student & 9 & 7.83 \\
\hline Total & 115 & 100 \\
\hline
\end{tabular}

\begin{tabular}{|c|c|c|}
\hline Diagnosis & Number of Patients & Percentage \\
\hline MDD & 66 & 57.39 \\
\hline GAD & 14 & 12.17 \\
\hline Panic disorder & 7 & 6.09 \\
\hline Adjustment disorder & 5 & 4.35 \\
\hline PTSD & 7 & 6.09 \\
\hline No Diagnosis & 16 & 13.91 \\
\hline Total & 115 & 100 \\
\hline
\end{tabular}

Table 2: Psychiatric morbidity.

With regard to profile of psychiatric disorders, 66 (57.39\%) of our subjects had major depressive disorder, $14(12.17 \%)$ had generalized anxiety disorder, 7 (6.09\%) had panic disorder, 7 (6.09\%) had posttraumatic stress disorder and $5(4.35 \%)$ had adjustment disorder. 16 (13.91\%) of our subjects where not found to have any psychiatric disorder (Table 2).

\section{Discussion}

The current study intended to find the socio-demographic profile and psychiatric morbidity in the patients who visited the mental health camp four months after the 2014 devastating floods in Srinagar. Females outnumbered males in our study with female to male ratio of $2: 1$. This is in accordance with the epidemiological studies on flood victims which have found females to be more frequently affected by psychiatric disorders than males [15-17]. Female preponderance in our study could be due to the fact that females have more brooding ruminations than males. In a community sample, engagement in brooding/intrusive rumination was reported more commonly in female adolescents than male adolescents and there was a positive relationship between brooding rumination and depressive symptoms $[18,19]$. In addition, mere exposure to a stressful event is not sufficient to cause a psychiatric disorder rather the subjective appraisal is also important and studies have shown females to appraise the traumatic events more and think over it repeatedly [20]. Major depressive disorder (57.39\%), anxiety disorders (18.26\%), post-traumatic stress disorder (6.09\%) and adjustment disorder (4.35\%), were the disorders diagnosed in people who visited us. Depression, anxiety, and PTSD are the most commonly found psychiatric disorders in people affected by floods [1] Similar results have been found in previous studies of water damage after Hurricanes and the summer 2007 floods in England [21,22]. More general studies on the impact of flooding on health reported significant PTSD findings in the first 6-24 months after flooding [23]. Overall, depression is increasingly experienced by people affected by floods [24-26] and this pattern was not only found in adults but also in children [27]. Studies have shown depression more in people affected by floods as compared to those who were not-affected by floods [28-31]. Although this was not found to be the case in an Australian study conducted with older adults [32]. Similar to depression, higher levels of anxiety disorders were found in those exposed to floods than non-exposed individuals [28-30,32]. Studies which compared the prevalence of PTSD in flood affected areas with those of non-affected areas have indicated a higher prevalence of PTSD or PTSD-related symptomatology in the flooded area $[1,28,29,32,33]$. It has also been suggested that PTSD or PTSD-related symptoms could be responsible for the development of other psychiatric disorders such as depression, anxiety or substance abuse disorders [34]. Percentage of patients with PTSD in our study was rather low as compared to previous studies. Margoob et al. found that a sizeable number of outpatient cases were suffering from PTSD, besides depressive disorders but these patients are just the tip of the iceberg as suggested by population based figures [35]. 
So, one possible reason for our lower results for PTSD could be that our study was not a community study, as were the previous studies in flood affected areas, and the patients with PTSD have not visited the camp.

Disasters including floods are inevitable truth of our life and have been part of human civilizations. Besides having its effect on physical health of affected populations, disasters also have substantial effect on their mental health [36]. Mental health professionals can play a multidimensional role in a disaster response team from educating, training, negotiating, administrative, fund raising, collaborative skill transferring, treating, advocating and rehabilitating [37]. Thinking from 'when' the disaster strikes to 'if' the disaster strikes has necessitated a paradigm shift from relief centered post-disaster management to a holistic, integrated and preventive approach based upon principles of disaster prevention, preparedness and mitigation. 37 Therefore responding to the emotional and psychological needs of the affected population and beginning community based group interventions as early as possible can help to mitigate the development of psychiatric disorders in the affected people.

\section{Conclusion}

To conclude, large numbers of people are potentially in need of psychological attention following exposure to a disaster such as floods. Following such events appropriate support from community and access to Primary Care services would be important in detecting distress. The people, who are at potential risk of developing psychiatric disorders such as those in poor health and those who have been relocated, may benefit from targeted mental health services following a disaster like floods. $57.39 \%$ of our subjects had major depressive disorder, $12.17 \%$ had generalized anxiety disorder, $6.09 \%$ had panic disorder, $6.09 \%$ had post-traumatic stress disorder and $4.35 \%$ had adjustment disorder. Researchers, practitioners and policy-makers may be able to benefit from information generated by this study and thus will work in favor of mental well-being of people affected by floods.

Being a camp based study, its results can't be generalized into the community wherein post-floods burden of psychiatric disorders in common and PTSD in particular, is very high. In addition, for the psychiatric diagnosis we relied solely on MINIInternational Neuropsychiatric Interview (MINI-Plus), without taking into consideration the pre-floods psychological distress level, history of exposure to any other traumatic event, family history of psychopathology, and/or psychosocial support they received and thus further limiting the generalizability of these results.

\section{References}

1. Alderman K, Turner LR, Tong S (2012) Floods and human health: A systematic review. Environ Int 47: 37-47.

2. Ramin BM, McMichael AJ (2009) Climate change and health in sub-Saharan Africa: A case-based perspective. EcoHealth 6: 52.

3. Du W, FitzGerald GJ, Clark M, Hou XY (2010) Health impacts of floods. Prehospital and Disaster Medicine 25: 265-272.

4. Fernandez A, Black J, Jones M, Wilson L, Salvador-Carulla L, et al. (2015) Flooding and mental health: a systematic mapping review. PloS One 10: e0119929

5. Liu A, Tan H, Zhou J, Li S, Yang T, et al. (2006) An epidemiologic study of posttraumatic stress disorder in flood victims in Hunan China. Can J Psychiatry 51: $350-354$

6. Heo JH, Kim MH, Koh SB, Noh S, Park JH, et al. (2008) A prospective study on changes in health status following flood disaster. Psychiatry Investig 5: 186-192.

7. Reacher M, McKenzie K, Lane C, Nichols T, Kedge I, et al. (2004) Health impacts of flooding in Lewes: a comparison of reported gastrointestinal and other illness and mental health in flooded and non-flooded households. Commun Dis Public Health 7: 39-46.

8. Friel S, Bowen $\mathrm{K}$, Campbell-Lendrum D, Frumkin $\mathrm{H}$, McMichael AJ, et al (2011) Climate change, non-communicable diseases, and development: the relationships and common policy opportunities. Annu Rev Public Health 32 133-147.

9. Assanangkornchai S, Tangboonngam SN, Sam-angsri N, Edwards JG (2007) A Thai community's anniversary reaction to a major catastrophe. Stress and Health 23: 43-50.

10. Norris FH, Baker CK, Murphy AD, Kaniasty K (2005) Social support mobilization and deterioration after Mexico's 1999 flood: Effects of context, gender, and time. Am J Community Psychol 36: 15-28.

11. Vachiramon V, Busaracome P, Chongtrakool P, Puavilai S (2008) Skin diseases during floods in Thailand. J Med Assoc Thai 91: 479-484.

12. Warraich H, Zaidi AK, Patel K (2011) Floods in Pakistan: A public health crisis. Bulletin of the World Health Organization 89: 236-237.

13. Chung MC, Jalal S, Khan NU (2014) Posttraumatic stress disorder and psychiatric comorbidity following the 2010 flood in Pakistan: Exposure characteristics, cognitive distortions, and emotional suppression. Psychiatry 77: 289-304

14. Lecrubier Y, Sheehan DV, Weiller E, Amorim P, Bonora I, et al. (1997) The Mini International Neuropsychiatric Interview (MINI). A short diagnostic structured interview: Reliability and validity according to the CIDI. Eur Psychiatry 12: 224-231.

15. Aslam N, Kamal A (2016) Stress, anxiety, depression, and posttraumatic stress disorder among general population affected by floods in Pakistan. Pakistan Journal of Medical Research 55: 29.

16. Ishikawa M, Yamamoto N, Yamanaka G, Suwa K, Nakajima S, et al. (2013) Disaster-related psychiatric disorders among survivors of flooding in Ladakh India. Int J Soc Psychiatry 59: 468-473.

17. Mason V, Andrews H, Upton D (2010) The psychological impact of exposure to floods. Psychol Health Med 15: 61-73.

18. Jose PE, Weir KF (2013) How is anxiety involved in the longitudinal relationship between brooding rumination and depressive symptoms in adolescents? J Youth Adolesc 42: 1210-1222.

19. C'de Baca J, Castillo D, Qualls C (2012) Ethnic differences in symptoms among female veterans diagnosed with PTSD. J Trauma Stress 25: 353-357.

20. Aslam N, Kamal A (2014) Frequency of posttraumatic stress disorder (PTSD) among flood affected individuals. Pak Armed Forces Med J 64: 100-104.

21. Abramson D, Stehling-Ariza T, Garfield R, Redlener I (2008) Prevalence and predictors of mental health distress post-Katrina: findings from the Gulf coast child and family health study. Disaster Med Public Health Prep 2: 77-86.

22. Paranjothy S, Gallacher J, Amlôt R, Rubin GJ, Page L, et al. (2011) Psychosocia impact of the summer 2007 floods in England. BMC Public Health 11: 145.

23. Neria Y, Nandi A, Galea S (2008) Post-traumatic stress disorder following disasters: A systematic review. Psychol Med 38: 467-480.

24. North CS, Kawasaki A, Spitznagel EL, Hong BA (2004) The course of PTSD, major depression, substance abuse, and somatization after a natural disaster. J Nerv Ment Dis 192: 823-829.

25. Ginexi EM, Weihs K, Simmens SJ, Hoyt DR (2000) Natural disaster and depression: a prospective investigation of reactions to the 1993 midwest floods. Am J Community Psychol 28: 495-518.

26. Tyler KA, Hoyt DR (2000) The effects of an acute stressor on depressive symptoms among older adults: The moderating effects of social support and age. Research on Aging 22: 143-164.

27. Felton JW, Cole DA, Martin NC (2013) Effects of rumination on child and adolescent depressive reactions to a natural disaster: The 2010 Nashville flood. J Abnorm Psychol 122: 64-73.

28. Azuma K, Ikeda K, Kagi N, Yanagi U, Hasegawa K, et al. (2014) Effects of water-damaged homes after flooding: health status of the residents and the environmental risk factors. Int J Environ Health Res 24: 158-175.

29. Maltais D, Lachance L, Fortin M, Lalande G, Robichaud S, et al. (2000) 
Citation: Bhat BA (2018) Socio-Demographic Profile and Psychiatric Morbidity of Flood Victims in a Mental Health Camp. J Psychiatry 21: 449. doi:10.4172/2378-5756.1000449

Psychological and physical health of the July 1996 disaster victims: A comparative study between victims and non-victims. Santé mentale au Québec 25: 116-137.

30. Wind TR, Joshi PC, Kleber RJ, Komproe IH (2013) The impact of recurrent disasters on mental health: a study on seasonal floods in northern India. Prehosp Disaster Med 28: 279-285.

31. Jones E, Gupta S, Murphy A, Norris F (2011) Inequality, socio-economic status, and social support in post-disaster mental health in Mexico. Human Organization 70: 33-43

32. Bei B, Bryant C, Gilson KM, Koh J, Gibson P, et al. (2013) A prospective study of the impact of floods on the mental and physical health of older adults. Aging Ment Health 17: 992-1002.
33. Auger C, Latour S, Trudel M, Fortin M (2000) Post-traumatic stress disorder. After the flood in Saguenay. Can Fam Physician 46: 2420-2427.

34. McMillen C, North C, Mosley M, Smith E (2002) Untangling the psychiatric comorbidity of posttraumatic stress disorder in a sample of flood survivors. Compr Psychiatry 43: 478-485.

35. Margoob MA, Ahmad SA (2006) Community prevalence of adult post-traumatic stress disorder in south Asia: Experience from Kashmir. JK-Practitioner 13 S18-S25.

36. Kim SC, Plumb R, Gredig QN, Rankin L, Taylor B (2008) Medium-term postKatrina health sequelae among New Orleans residents: predictors of poor mental and physical health. J Clin Nurs 17: 2335-2342.

37. Math SB, Nirmala MC, Moirangthem S, Kumar NC (2015) Disaster management: Mental health perspective. Indian J Psychol Med 37: 261-271. 